\title{
Application of GIS based data driven evidential belief function model to predict groundwater potential zonation
}

\begin{abstract}
The objective of this paper is to exploit potential application of an evidential belief function (EBF) model for spatial prediction of groundwater productivity at Langat basin area, Malaysia using geographic information system (GIS) technique. About 125 groundwater yield data were collected from well locations. Subsequently, the groundwater yield was divided into high $(\geqslant 11 \mathrm{~m} 3 / \mathrm{h})$ and low yields $(<11 \mathrm{~m} 3 / \mathrm{h})$ respectively, based on the groundwater classification standard recommended by Department of Mineral and Geosciences (JMG), Malaysia. Out of all of the borehole data, only 60 wells possessed higher yield at $\geqslant 11 \mathrm{~m} 3 / \mathrm{h}$. Further, these wells were randomly divided into a testing dataset $70 \%$ (42 wells) for training the model and the remaining 30\% (18 wells) was used for validation purpose. To perform cross validation, the frequency ratio (FR) approach was applied into remaining groundwater wells with low yield to show the spatial correlation between the low potential zones of groundwater productivity. A total of twelve groundwater conditioning factors that affect the storage of groundwater occurrences were derived from various data sources such as satellite based imagery, topographic maps and associated database. Those twelve groundwater conditioning factors are elevation, slope, curvature, stream power index (SPI), topographic wetness index (TWI), drainage density, lithology, lineament density, land use, normalized difference vegetation index (NDVI), soil and rainfall. Subsequently, the Dempster-Shafer theory of evidence model was applied to prepare the groundwater potential map. Finally, the result of groundwater potential map derived from belief map was validated using testing data. Furthermore, to compare the performance of the EBF result, logistic regression model was applied. The success-rate and prediction-rate curves were computed to estimate the efficiency of the employed EBF model compared to LR method. The validation results demonstrated that the success-rate for EBF and LR methods were $83 \%$ and $82 \%$ respectively. The area under the curve for prediction-rate of EBF and LR methods were calculated $78 \%$ and $72 \%$ respectively. The outputs achieved from the current research proved the efficiency of EBF in groundwater potential mapping.
\end{abstract}

Keyword: Groundwater potential; Evidential belief function (EBF); Logistic regression (LR); GIS; Remote sensing; Malaysia 